\title{
Erratum to: Adherence and Delivery: Implementation Quality and Program Outcomes for the Seventh-Grade keepin' it REAL Program
}

\author{
Jonathan Pettigrew • John W. Graham • \\ Michelle Miller-Day • Michael L. Hecht • \\ Janice L. Krieger • Young Ju Shin
}

Published online: 2 October 2014

(C) Society for Prevention Research 2014

Erratum to: Prev Sci

DOI: 10.1007/s11121-014-0459-1

The original version of this article unfortunately contained an error in the standard deviation of the number of students in participating schools. The correct statistic is now reported $(M=552, S D=272)$.

The online version of the original article can be found at http://dx.doi.org/ 10.1007/s11121-014-0459-1.

J. Pettigrew $(\varangle) \cdot$ M. Miller-Day $\cdot$ M. L. Hecht $\cdot$ Y. J. Shin

Department of Communication Arts and Sciences, Penn State, State

College, PA, USA

e-mail: jpettigrew@utk.edu

J. W. Graham

Department of Biobehavioral Health, Penn State, State College, PA,

USA

J. W. Graham • M. L. Hecht

Prevention Research Center, Penn State, State College, PA, USA

\section{J. L. Krieger}

School of Communication, The Ohio State University, Columbus,

$\mathrm{OH}$, USA

Present Address:

J. Pettigrew

School of Communication Studies, University of Tennessee, 293

Communications Building, Knoxville, TN 37996, USA

Present Address:

M. Miller-Day

Department of Communication Studies, Chapman University,

Orange, CA, USA

Present Address:

Y. J. Shin

Department of Communication Studies, Indiana University-Purdue

University Indianapolis, Indianapolis, IN, USA 